Editorial

\title{
Wine Aging Technologies
}

\author{
Maria Del Alamo-Sanza ${ }^{1, *(\mathbb{D}) \text { and Ignacio Nevares }}{ }^{2, *(\mathbb{D})}$ \\ 1 Department of Analytical Chemistry, UVaMOX-Higher Tech. Col. of Agricultural Engineering, \\ Universidad de Valladolid, 34001 Palencia, Spain \\ 2 Department of Agroforestry Engineering, UVaMOX-Higher Tech. Col. of Agricultural Engineering, \\ Universidad de Valladolid, 34001 Palencia, Spain \\ * Correspondence: maria.alamo.sanza@uva.es (M.D.A.-S.); ignacio.nevares@uva.es (I.N.)
}

Received: 7 March 2019; Accepted: 7 March 2019; Published: 12 March 2019

check for updates

Wine aging is a desirable and valuable process, commonly used to improve wine quality, and traditionally carried out in oak wooden casks. The correct use of oak barrels and the ever-increasing demand for barrels in different production areas of the world has led to a constant search for technological alternatives to reproduce the chemical and physical processes undergone by wines during their stay in barrels.

This Special Issue aims to publish a compilation of original research and reviews that cover different aspects of the aging processes of wine in casks and other alternative systems that reproduce, with different technologies, the transformations that take place in the barrel. This special issue has seven works, the first, titled "Different Woods in Cooperage for Oenology: A Review" [1] by Ana Martínez-Gil et al., focused on the possible use of different woods to the traditional ones in the wine aging process. New trends in the use of barrels have resulted in an increased demand for oak wood in the cooperage. This growing demand has led to the use of woods within the genus Quercus other than those traditionally used (Quercus alba, Quercus petraea, and Quercus robur) and even wood of different genera. The species of the genus Quercus, such as Quercus pyrenaica Willd, Quercus faginea Lam, Quercus humboldtti Bonpl, Quercus oocarpa Liebm, Quercus frainetto Ten, and other genera, such as Robinia pseudoacacia L. (false acacia), Castanea sativa Mill, Prunus avium L. and Prunus cereaus L. (cherry), Fraxinus excelsior L. (European ash), Fraxinus americana L. (American ash), Morus nigra L. and Morus alba L. have been studied as possible sources of wood suitable for cooperage. The chemical characterization of these woods is fundamental to be able to adapt the treatment of the cooperage and therefore obtain a wood with enological qualities suitable for the treatment of wines. This review aims to summarize the different species that have been studied as possible new sources of wood for enology, defining the extractable composition of each of them and their use in wine.

The second work entitled "Study of High Power Ultrasound for Oak Wood Barrel Regeneration: Impact on Wood Properties and Sanitation Effect" [2], by Breniauxa et al., presented the ability of high power ultrasound (HPU) to ensure oak barrel sterilization and wood structure preservation. Optimization was performed in terms of temperature and time. The impact of the HPU process on the porous material was also characterized. In this research, several wood characteristics were considered, such as the specific surface area, hydrophobicity, oxygen desorption, and spoilage microorganisms after treatment. The study showed that the microbial stabilization could be obtained with HPU $60{ }^{\circ} \mathrm{C} / 6 \mathrm{~min}$. The results obtained show that microorganisms are impacted up to a depth of $9 \mathrm{~mm}$, with a Brettanomyces bruxellensis population $<1 \log \mathrm{CFU} / \mathrm{g}$. The operating parameters used during the HPU treatment can also impact wood exchange surface and oxygen desorption kinetics indicating that tartrate was removed. Indeed, the total oxygen desorption rate was recovered after HPU treatment close to a new oak barrel and this may indicate that there is no impact on the ultrastructure (vessel, pore size, or rays). Finally, wood wettability can also be impacted depending on the temperature and the duration of exposure. 
The third work was carried out within the scope of alternative aging systems, with the title "Oxygen Consumption by Red Wines under Different Micro-Oxygenation Strategies and Q. Pyrenaica Chips. Effects on Color and Phenolic Characteristics" [3] by Sánchez-Gómez et al. described the importance of micro-oxygenation (MOX) as a key factor in obtaining a final wine that is more stable over time and with similar characteristics as barrel-aged wines. Therefore, the oxygen dosage added must be that which the wine can consume to develop correctly. The oxygen consumption of red wine determines its properties so it is essential that micro-oxygenation is managed properly. This paper shows the results from the study of the influence on red wine of two different MOX strategies: floating oxygen dosage (with dissolved oxygen setpoint of $50 \mu \mathrm{g} / \mathrm{L}$ ) and fixed oxygen dosage $(3 \mathrm{~mL} / \mathrm{L} \cdot \mathrm{month}$ ). The results indicated that the wines consumed all the oxygen provided: those from fixed MOX received between 3 and 3.5 times more oxygen than the floating MOX strategy; the oxygen contribution from the air entrapped in the wood was more significant in the latter. Wines aged with wood and MOX showed the same color and phenolic evolution as those aged in barrels, which demonstrates the importance of MOX management. Despite the differences in oxygen consumption, it was not possible to differentiate wines from the different MOX strategies at the end of the aging period. Another work in the same field is that of Rubio-Bretón et al. entitled "Use of Oak Fragments during the Aging of Red Wines. Effect on the Phenolic, Aromatic, and Sensory Composition of Wines as a Function of the Contact Time with the Wood [4]. This paper studied the effect of the use of oak fragments on the volatile, phenolic, and sensory characteristics of Tempranillo red wines, as a function of the contact time between the wood and the wine. The results showed important changes in the wines' colorimetric parameters after two months of contact time. Extraction kinetics of volatile compounds from the wood were highest during the first month of contact for chips, variable for staves, and slower and continuous over time for barrels. Wines macerated with fragments showed the best quality in short periods of aging, while barrel-aged wines improved over the time they spent in the barrel. In addition, the results allowed an analytical discrimination between the wines aged with oak fragments and those aged in oak barrels, and between chips and staves, just as at the sensory level with triangular taste tests. In conclusion, the use of oak fragments is a suitable practice for the production of red wines, which may be an appropriate option for wines destined to be aged for short periods. The fifth paper, "New Strategies to Improve Sensorial Quality of White Wines by Wood Contact" [5] by Alañón et al., focused on the importance of quantitative and qualitative compounds of the wood depending on the species, its origins, and the treatments applied in cooperages. Traditionally, oak wood species are most often used in cooperage, specifically Quercus alba, known as American oak, and Quercus robur and Quercus petraea, both known as French oak. Although the use of wood contact is very common for red wines, its use is still restricted in the case of white wines. However, this topic is particularly interesting, since due to the sensorial benefits of wood contact, the option for aging white wines in barrels or chips could be chosen by winemakers. This review compiles the novel strategies applied to white wines using wood contact in recent years with the aim to increase wine quality and sensorial features.

Mohekar et al. presented their work "Effects of Fining Agents, Reverse Osmosis and Wine Age on Brown Marmorated Stink Bug (Halyomorpha halys) Taint in Wine" [6], in which is they described how trans-2-decenal and tridecane are compounds found in wine made from brown marmorated stink bug (BMSB)-contaminated grapes. The effectiveness of the post-fermentation processes on reducing their concentration in finished wine and their longevity during wine aging was evaluated. Red wines containing trans-2-decenal were treated with fining agents and put through reverse osmosis filtration. The efficiency of these treatments was determined using chemical analysis (multidimensional gas chromatography-mass spectrometry (MDGC-MS)) and sensory descriptive analysis. Tridecane and trans-2-decenal concentrations in red and white wine were determined at bottle aging durations of $0,6,12$, and 24 months using MDGC-MS. Reverse osmosis was found to be partially successful in removing trans-2-decenal concentrations from finished wine. While tridecane and trans-2-decenal concentrations decreased during bottle aging, post-fermentative fining treatments were not effective at removing these compounds. Although French oak did not alter the concentration of tridecane and 
trans-2-decenal in red wine, it did mask the expression of BMSB-related sensory characters. Because of the ineffectiveness of removing BMSB taint post-fermentation, BMSB densities in the grape clusters should be minimized so that taints do not occur in the wine.

And finally the paper of Rodríguez et al., entitled "Novel Method for the Identification of the Variety of Grape Using Their Capability to Form Gold Nanoparticles" [7], showed the possibilities of gold nanoparticles (AuNPs) obtained using musts (freshly prepared grape juices where solid peels and seeds have been removed) as a reducing and capping agent. Transmission electron microscope images showed that the formed AuNPs were spherical and their size increased with the amount of must used. The size of the AuNPs increased with an increase in the total polyphenol index (TPI) of the variety of grape. The kinetics of the reaction monitored using UV-VIS showed that the reaction rates were related to the chemical composition of the musts and specifically to the phenols that acted as reducing and capping agents during the synthesis process. Since the particular composition of each must produces AuNPs of different sizes and at different rates, color changes can be used to discriminate the variety of grape. This new technology can be used to avoid fraud.

We would like to acknowledge the chance offered by MDPI, the publisher, to coordinate and serve as guest editors of this special issue of Beverages on the topic of wine aging technologies, which we have pleasantly carried out. We are very grateful to the authors who have generously shared their scientific knowledge and experience with others through their contribution to this special issue.

Conflicts of Interest: The authors declare no conflict of interest.

\section{References}

1. Martínez-Gil, A.; Del Alamo-Sanza, M.; Sánchez-Gómez, R.; Nevares, I. Different Woods in Cooperage for Oenology: A Review. Beverages 2018, 4, 94. [CrossRef]

2. Breniaux, M.; Renault, P.; Meunier, F.; Ghidossi, R. Study of High Power Ultrasound for Oak Wood Barrel Regeneration: Impact on Wood Properties and Sanitation Effect. Beverages 2019, 5, 10. [CrossRef]

3. Sánchez-Gómez, R.; Nevares, I.; Martínez-Gil, A.M.; Del Alamo-Sanza, M. Oxygen Consumption by Red Wines under Different Micro-Oxygenation Strategies and Q. Pyrenaica Chips. Effects on Color and Phenolic Characteristics. Beverages 2018, 4, 69. [CrossRef]

4. Rubio-Bretón, P.; Garde-Cerdán, T.; Martínez, J. Use of Oak Fragments during the Aging of Red Wines. Effect on the Phenolic, Aromatic, and Sensory Composition of Wines as a Function of the Contact Time with the Wood. Beverages 2018, 4, 102. [CrossRef]

5. Alañón, M.E.; Díaz-Maroto, M.C.; Pérez-Coello, M.S. New Strategies to Improve Sensorial Quality of White Wines by Wood Contact. Beverages 2018, 4, 91. [CrossRef]

6. Mohekar, P.; Osborne, J.; Tomasino, E. Effects of Fining Agents, Reverse Osmosis and Wine Age on Brown Marmorated Stink Bug (Halyomorpha halys) Taint in Wine. Beverages 2018, 4, 17. [CrossRef]

7. Rodriguez, S.; De Lamo, B.; García-Hernández, C.; García-Cabezón, C.; Rodríguez-Méndez, M.L. Novel Method for the Identification of the Variety of Grape Using Their Capability to Form Gold Nanoparticles. Beverages 2018, 4, 26. [CrossRef]

(C) 2019 by the authors. Licensee MDPI, Basel, Switzerland. This article is an open access article distributed under the terms and conditions of the Creative Commons Attribution (CC BY) license (http://creativecommons.org/licenses/by/4.0/). 